\title{
Behavior change programs in Africa: reasons for a perpetual recommencement
}

\begin{abstract}
In terms of population health status, African region has some of the worst performing indicators in the world. However, countries are striving to achieve the international health development goals specified in the PHC, MDGs and SDGs. The observation is that strategies used are essentially those of behavior change (IEC, HE, BCC, etc.). While unhealthy behaviors respond to a "social gradient" so that without social inequalities in health reduction, achieving sustainable improvement results is almost impossible. We must raise the social level of people in order to be able to obtain healthier behaviors. The expiry of the SDGs is expected to prompt countries in the region to move towards Health Promotion approach for the social inequalities in health reduction and therefore a sustainable improvement of the populations' health status.
\end{abstract}

Keywords: health improvement, behavior change communication, social gradient, social determinants of health, social inequalities in health, Africa
Volume 8 Issue 2 - 2019

\author{
David S Houéto,' Namoudou Kéita, ${ }^{2}$ Morris \\ Sheriff, ${ }^{2}$ Kofi Busia ${ }^{2}$ \\ 'University of Parakou, West Africa \\ ${ }^{2}$ Department of Health System Strengthening, West African \\ Health Organization (WAHO), West Africa
}

Correspondence: David S Houéto, School of public health, University of Parakou, BP I23, Parakou, Benin, Tel: +229 9727 75 I5, Email dhoueto@gmail.com

Received: March 28, 2019 | Published: April 24, 2019
Abbreviations: AIDS, acquired immunodeficiency syndrome; $\mathrm{BCC}$, behavior change communication; $\mathrm{C} 4 \mathrm{D}$, communication for development; FP, family planning; HE, health education; HIV, human immunodeficiency virus; IEC, Information, education, communication for health; IMCI-C, integrated management of childhood illnesses at community level; LLIIMN, long-lasting insecticide-impregnated mosquito net; $\mathrm{MCH}$, mother and child health; MDGs, millennium development goals; PHC, primary health care; $\mathrm{RH}$, reproductive health; SDH, social determinants of health; SIH, social inequalities in health; SDGs, sustainable development goals; TFPs, technical and financial partners; WAHS, water, hygiene and sanitation; WHO, world health organization

\section{Introduction}

Africa is faced with a triple burden of communicable, noncommunicable and socio-behavioral diseases, along with illiteracy, poverty and underdevelopment. ${ }^{1}$ Health authorities in the region at all levels are well aware of the situation of people's worse-being. With the aim of changing the situation towards an improvement of indicators of populations' health status, they nevertheless privilege strategies such as information, education and communication (IEC), health education (HE), behavior change communication (BCC), social mobilization, social marketing, etc. ${ }^{2}$ Health professionals with projects and programs continue to evolve according to a logic which considers that public information disseminated through well-developed communication tools is enough to produce behavioral changes, therefore the development of IEC, HE, BCC and communication interventions. For priority health programs in countries of the region, such as maternal and child health (MCH), youth and adolescent health and family planning/reproductive health (FP/RH), Malaria, Integrated Management of Childhood Illnesses at the Community Level (IMCI-C), Nutrition, HIV/AIDS, Water-Hygiene-Sanitation (WASH), Gender, Female Genital Mutilation, Climate Change, animal health, etc., for example, the strategies used target behavioral change mainly through $\mathrm{BCC}$ with mixed results. According to $\mathrm{WHO},{ }^{3}$ the reasons for this failure are that most communications (IEC, BCC, etc.) and HE interventions remain focused on individual lifestyles and health. Similarly, Laverack ${ }^{4} \&$ Whitlock et al., ${ }^{5}$ noted that information alone cannot bring about a change in behavior. Our objective here is to share the findings of a regional study aimed at understanding the reasons for the lower performance of behavior change strategies in Africa.

\section{The practice of implementing BCC strategies}

For details on the process of implementation of BCC strategies, there are many guiding documents that we invite to consult such as Bougaïré-Zangréyanogho et al., ${ }^{6}$ or the National Cancer Institute. ${ }^{7}$ It is common to see projects/programs organize awareness-raising campaigns in the streets of big cities in countries of the region aiming at adoption by households of the use of this or that social product, e.g. the Long-Lasting Insecticide-impregnated Mosquito Net (LLIIMN), family planning modern methods, etc. In addition, there is a "pressure" on countries from the "technical and financial partners" (TFPs) in the development of projects designed for the most part in a top-down vision, neglecting the empowerment aspect of the target populations. ${ }^{4,8}$ In the absence of proper guidelines for actions at the health systems level in most of countries, and with the financial power, it is the TFPs intervention method that is then implemented. ${ }^{2}$ Despite these interventions in the region, progress in behavior change is struggling to show prominence and has not been able to contribute to the achievement of the Millennium Development Goals (MDGs). ${ }^{8}$

\section{New solutions are needed}

Behaviors respond to a social gradient and to change them, it is necessary to address SDH for the reduction of social inequalities in health (SIH), which are the main causes. ${ }^{9-11}$ Social gradient refers to the frequency (e.g. of a health problem) steadily increases from the most favored categories to the most disadvantaged categories. ${ }^{12}$ Unhealthy behaviors respond precisely to this social gradient and are mostly observed in the African region, particularly among people with low social level. SIH are the consequences of the socio-political organization of the nations with, among others, an expression through unhealthy behaviors and diseases. ${ }^{13}$ The lowest social classes are the most affected by these behaviors and diseases compared with higher social classes. For example, Chigudu ${ }^{14}$ states that Ebola hemorrhagic fever is the biological expression of SIH. The effective mechanism of action for behavioral change should then be based on the root causes of SIH as Taket ${ }^{15}$ states in Figure 1 and the WHO Commission report on SDH. ${ }^{11}$ Achieving sustainable behavior change goals then involves 
raising the social level of people and therefore developing a high level of health literacy. Health literacy refers, in general, to individuals' ability to "access, understand and use information to promote and stay healthy" for themselves, their families and their communities. ${ }^{3}$ It will lead to the empowerment needed to address SDH through creation of critical consciousness. Critical consciousness includes individual consciousness (awareness of one's problem); collective consciousness (we are not alone in having a problem); social consciousness (the way society is organized influences problems) and; political consciousness (the solution to structural problems involves collective action). ${ }^{16}$ Development of health literacy presupposes a strong commitment of governments to the systematic schooling of all children as prescribed in the constitution of all countries in the region (Figure 1).

\section{The Health Gradient}

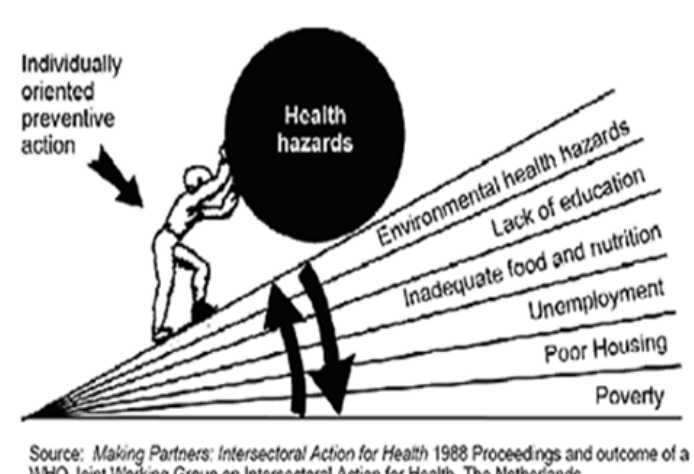
Source: Mabing Partners: Intersectoral Action for Heath 1988 Proceedngs and
WHO Joint Woiking Group on Intersectoral Action for Health, The Netherlands.

Figure I The health gradient.

\section{Health promotion remains the perfect solution}

Health promotion is a process to address the social determinants of health (SDH), which is defined as the conditions in which people are conceived, born, live, grow, work and age, as well as mechanisms put in place to address disease. ${ }^{11}$ In order to achieve sustainable change in health behavior, one should adopt health promotion as part of an ecological model of health; a systemic perspective and; a focus on organizational development and change of the entire system in which individual evolves. ${ }^{17}$ Health promotion is a concrete approach to achieving greater health equity. African countries gathered around WHO African Region have recognized this since the Mexico City Conference in $2000^{18}$ and commitment to Health Promotion has become the priority and the main approach to health systems management. WHO African Region with the Ouagadougou Declaration ${ }^{19}$ and the African Regional Strategy for Health Promotion ${ }^{20}$ reiterated the recognition of the prominent place to be given to health promotion in Africa to achieve sustainable results in behavior change. Research and case studies from around the world provide evidence that health promotion is truly effective. Health promotion strategies can create and modify lifestyles, as well as the social, economic, and environmental conditions that determine health. ${ }^{15,21}$ For interventions with a high impact on health, Frieden ${ }^{21}$ (Figure 2) noted that they must target SDH in a population approach.

When considering the health impact pyramid, ${ }^{21}$ the bottom tier represents changes in socioeconomic factors that allow change of social status at a level higher than the one that can produce more unhealthy behaviors and damages health. This kind of interventions are for example poverty reduction, improved education, addressing unemployment, improved work conditions, etc. These interventions often referred to as social determinants of health help form the basic foundation of a society. ${ }^{11}$ Although the exact mechanisms by which socioeconomic status exerts its effects are not always apparent, poverty, low educational attainment, relative deprivation, and lack of access to sanitation increase exposure to environmental hazards. ${ }^{22,23}$ As Marmot ${ }^{9,10}$ stressed it, only the way our societies are organized can explain the distribution of these social determinants of health. That is why the World Health Organization's Commission on Social Determinants of Health he chaired reported that the "Social injustice is killing people on a grand scale" [10, p26]. So, addressing social determinants of health is a matter of social justice he said. ${ }^{9,10}$ The second tier of the pyramid ${ }^{21}$ represents interventions that change the environmental context to make healthy options the default choice, regardless of education, income, service provision, or other societal factors. The defining characteristic of this tier of intervention is that individuals would have to expend significant effort not to benefit from them. ${ }^{15}$ Strategies to create healthier environmental contexts include for instance designing communities to promote increased physical activity; enacting policies that encourage public transit, bicycling, and walking instead of driving; designing buildings to promote stair use; passing smoke-free laws; and taxing tobacco, alcohol, and unhealthy foods such as soda and other sugar-sweetened beverages. ${ }^{21}$ While cardiovascular disease risk factors (e.g., hypertension) are currently addressed at the individual level through screening and medication, changing the environmental context so that individuals can easily take heart-healthy actions in the normal course of their lives can have a greater population impact than clinical interventions that treat individuals..$^{15,21}$ As Frieden ${ }^{21}$ put it, modern diets contain many times the minimum daily requirement of sodium - mostly from packaged foods and restaurant meals - making it difficult for individuals to control their intake. ${ }^{15,24}$ Reducing dietary sodium can reduce hypertension at the population level. A healthier food environment can be created by decreasing salt in packaged foods. ${ }^{15,21,25,26}$

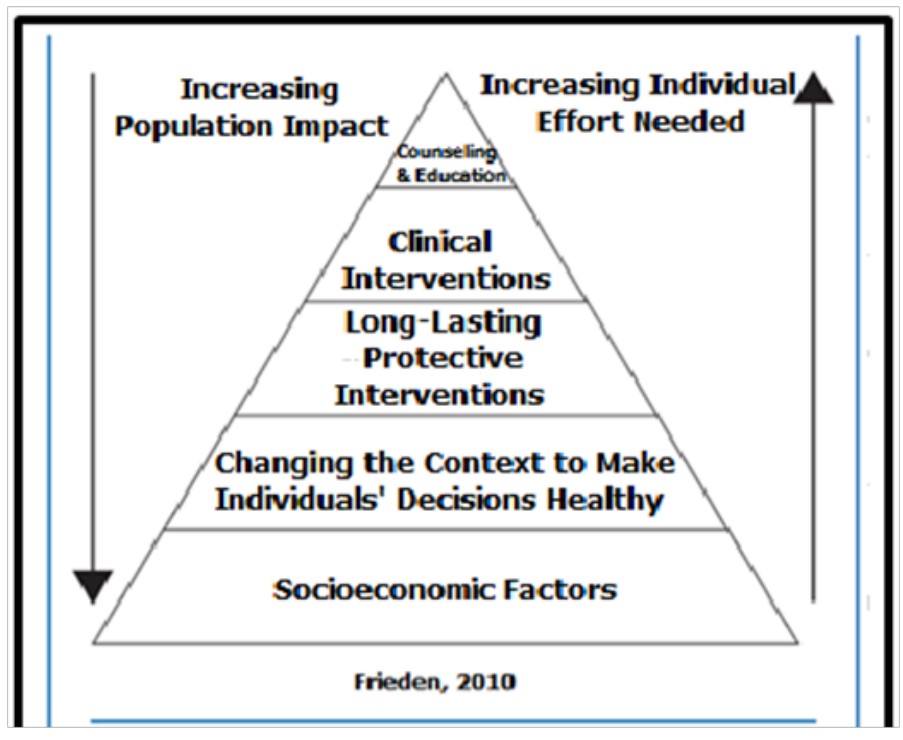

Figure 2 The health impact pyramid.

The third level of the Frieden's pyramid ${ }^{21}$ represents 1-time or infrequent protective interventions that do not require ongoing clinical care. These interventions generally have less impact than interventions 
represented by the bottom 2tiers because they necessitate reaching people as individuals rather than collectively. Historic examples include immunization, which prevents 2.5 million deaths per year among children globally. ${ }^{27}$ Other examples are smoking cessation programs that increase quit rates; life expectancy among men who quit at age 35 is almost 7years longer than for those who continue to smoke. ${ }^{28}$ Male circumcision, a minor outpatient surgical procedure, can decrease female-to-male HIV transmission by as much as $60 \% .{ }^{29}$ Scale-up could potentially prevent millions of HIV infections in subSaharan Africa. ${ }^{30,31}$ A single dose of azithromycin or ivermectin can reduce the prevalence of onchocerciasis, a major cause of blindness. ${ }^{32}$ The fourth level of the pyramid represents ongoing clinical interventions, of which interventions to prevent cardiovascular disease have the greatest potential health impact. Although evidence-based clinical care can reduce disability and prolong life, the aggregate impact of these interventions is limited by lack of access, erratic and unpredictable adherence, and imperfect effectiveness. ${ }^{21}$ Access can be limited even in systems that guarantee health coverage for all and is a much greater problem in countries without universal health care coverage ${ }^{21,33-35}$ Nonadherence is especially problematic for chronic conditions that are usually asymptomatic, such as hypertension, hyperlipidemia, and diabetes. At least a third of patients do not take medications as advised, and nonadherence cannot be predicted from socioeconomic or demographic characteristics..$^{20,36,37}$

The pyramid's fifth tier $^{21}$ represents health education (known in the African region also as IEC, $\mathrm{BCC}, \mathrm{C} 4 \mathrm{D}$, etc.), which is perceived by some as the essence of public health action but is generally the least effective type of intervention. ${ }^{4,5}$ The need to urge behavioral change is symptomatic of failure to establish contexts in which healthy choices are default actions. Freiden ${ }^{21}$ explained this with many examples: Counterbalances to our obesogenic environment include exhortations to increase physical activity and improve diet, which have little or no effect. More than one third of US adults, or 72million people, were obese in 2006, a dramatic increase over 1980. Two thirds of these individuals were counseled by a health care provider to lose weight, yet daily calorie and fat intake continues to rise ${ }^{38,39}$ Counseling, either within or outside the clinical context, is generally less effective than other interventions; successfully inducing individual behavioral change is the exception rather than the rule. For example, although clear, strong, and personalized smoking cessation advice, even in the absence of pharmacological treatment, doubles quit rates among smokers who want to stop and should be the norm in medical care, it still fails to help $90 \%$ of those who are motivated to quit. ${ }^{40,41}$ Nevertheless, educational interventions are often the only ones available, and when applied consistently and repeatedly may have considerable impact ${ }^{21}$ An example of a successful evidence-based educational intervention is trained peer counselors advising men who have sex with men about reducing HIV risk $^{42}$ (Figure 2).

The challenge now is to harness health promotion potential that exists in many sectors of society, in local communities and within families. It will be necessary to overcome the traditional compartmentalization existing within public authorities themselves, between governmental and non-governmental organizations, and between public and private sectors. Cooperation is critical, which implies the creation of new partnerships for health, on an equal basis, between different sectors, at all levels of the management of public affairs in order to see the outcome of the interventions which must focus on $\mathrm{SDH} .{ }^{3}$

\section{Conclusion}

Health is a complex phenomenon that cannot be improved simply by the use of communication approaches that are rather useful as adjuncts to root cause strategies. Unhealthy behaviors manifest themselves along a social gradient, so behavioral change interventions should be geared towards reducing the underlying causes of SIH. This will be the only alternative for the region to achieve the Sustainable Development Goals (SDGs).

\section{Acknowledgments}

None

\section{Conflict of interest}

Author declares that there are no conflicts of interest.

\section{References}

1. UN Platform on Social Determinants of Health (ILO, UNDP, UNFPA, UNICEF, WHO and UNAIDS). Joint statement of the UN Platform on Social Determinants of Health. Health in the post-2015 development agenda: need for a social determinants of health approach. 2012:18.

2. Houéto D, Valentini H. Health promotion in Africa: history and future prospects. Santé Publique. 2014;1:S9-S20.

3. World Health Organization. Statement of the 9th Shanghai Conference on Health Promotion. Geneva, Switzerland. 2016.

4. Laverack G. Health promotion practice: Building empowered communities. Open University Press, Berkshire, England. 2007:156.

5. Whitlock EP, Orleans CT, Pender N, et al. Evaluating primary care behavioral counseling interventions. Am J Prev Med. 2002;22(4):267-284.

6. Bougaïré-Zangréyanogho D, Barry-Waongo J, Zougmoré I, et al. Communication for behavior change (module XI). 3rd edn. Ouagadougou, Burkina Faso.

7. National Cancer Institute. Making Health Communication programmes work. 2002.

8. United Nations Economic Commission for Africa, African Union, African Development Bank and United Nations Development Programme. MDG Report 2015: Assessing Progress in Africa toward the Millennium Development Goals. Addis Ababa, Ethiopia. 2015.

9. Marmot M. Status Syndrome. London. Bloomsbury Publishing; 2004:288.

10. Marmot M. The Health Gap: The Challenge of an Unequal World. Bloomsbury Publishing; 2015:400.

11. World Health Organization (WHO). Bridging the gap in a generation: Building health equity by addressing the social determinants of health. Geneva. 2008.

12. Leclerc A, Kaminski M, Lang T. Unequal in the face of health: from observation to action. Revue Project. 2008:300. 
13. Houéto D. The social determinants of emerging infectious diseases in Africa. MOJ Public Health. 2019;8(2):57-63.

14. Chigudu S. Politics and epidemics. BMJ Talk Medicine. 2019.

15. Taket A. Making partners: Intersectoral Action for Health: Proceeding and Outcome for a Joint Working Group on Intersectoral Action for Health. Copenhagen. WHO; 1990.

16. Ninacs WA. À la recherche de l'empowerment collectif. Université de Moncton; 2011.

17. World Health Organization (WHO). Jakarta Declaration on Health Promotion in the 21st Century. 4th World Conference on Health Promotion. Geneva. 1997.

18. World Health Organization. Mexico's Ministerial Declaration for Health Promotion: Promoting Health: Making room for equity, from ideas to action. Fifth World Conference on Health Promotion, Mexico City, 5 June 2000. 2000.

19. World Health Organization. Ouagadougou Declaration on Primary Health Care and Health Systems in Africa: Improving Health in Africa in the New Millennium. International Conference on Primary Health Care and Health Systems in Africa, 28-30 April 2008b, Ouagadougou, Burkina Faso. 2008.

20. World Health Organization. African Regional Strategy for Health Promotion. Luanda, Angola. 2012.

21. Frieden TR. A framework for public health Action: The Health Impact Pyramid. American Journal of Public Health. 2010;100(4):590-595.

22. CSDH - Commission on social determinants of health. A conceptual framework for action on the social determinants of health. Geneva. WHO; 2007.

23. Wood D. Effect of child and family poverty on child health in the United States. Pediatrics. 2003;112(3 part 2):707-711.

24. Mattes RD, Donnelly D. Relative contributions of dietary sodium sources. J Am Coll Nutr. 1991;10(4):383-393.

25. Sacks FM, Svetkey LP, Vollmer WM, et al. Effects on blood pressure of reduced dietary sodium and the Dietary Approaches to Stop Hypertension (DASH) diet. DASH-Sodium Collaborative Research Group. N Engl J Med. 2001;344(1):3-10.

26. Danaei G, Ding EL, Mozaffarian D, et al. The preventable causes of death in the United States. PLoS Med. 2009;6(4):e1000058.

27. WHO, UNICEF, World Bank. State of the World's Vaccines and Immunization. 3rd edn. Geneva, Switzerland. World Health Organization; 2009.

28. Taylor DH Jr, Hasselblad V, Henley SJ, et al. Benefits of smoking cessation for longevity. Am J Public Health. 2002;92(6):990996.
29. Auvert B, Taljaard D, Lagarde E, et al. Randomized, controlled intervention trial of male circumcision for reduction of HIV infection risk: the ANRS 1265 Trial. PLoSMed. 2005;2(11):e298.

30. Nagelkerke NJ, Moses S, de Vlas SJ, et al. Modelling the public health impact of male circumcision for HIV prevention in high prevalence areas in Africa. BMC Infect Dis. 2007;7:16.

31. WHO/UNAIDS. New data on male circumcision and HIV prevention: policy and programme implications. Geneva, Switzerland. World Health Organization; 2007.

32. Melese M, Chidambaram J, Alemayehu W, et al. Feasibility of eliminating ocular Chlamydia trachomatis with repeat mass antibiotic treatments. JAMA. 2004;292(6):721-725.

33. Shah SM, Cook DG. Socio-economic determinants of casualty and NHS direct use. J Public Health (Oxf). 2008;30(1):75-81.

34. Lasser KE, Himmelstein DU, Woolhandler S. Access to care, health status, and health disparities in the United States and Canada: results of a cross-national population-based survey. $\mathrm{Am}$ J Public Health. 2006;96(7):1300-1307.

35. Schoen C, Doty MM. Inequities in access to medical care in five countries: findings from the 2001 Commonwealth Fund International Health Policy Survey. Health Policy. 2004;67(3):309-322.

36. Sbarbaro JA. Compliance: inducements and enforcements. Chest. 1979;76(6 Suppl):750-756.

37. Haynes RB, McKibbon KA, Kanani R. Systematic review of randomized trials of interventions to assist patients to follow prescriptions for medications. Lancet. 1996;348(9024):383386.

38. CDC. Prevalence of overweight and obesity among adults: United States, 2003-2004. Atlanta, GA. 2008.

39. Ogden CL, Carroll MD, McDowell MA, et al. Obesity among adults in the United States-no change since 2003-2004. Hyattsville, MD. National Center for Health Statistics; 2007.

40. Thorndike AN, Regan S, Rigotti NA. The treatment of smoking by US physicians during ambulatory visits: 1994-2003. Am J Public Health. 2007;97(10):1878-1883.

41. Fiore MC, Jaen CR, Baker TB, et al. Treating Tobacco Use and Dependence: 2008 Update. Clinical Practice Guideline. Rockville (MD). US Public Health Service; 2008.

42. US Preventive Services Task Force. Behavioral counseling to prevent sexually transmitted infections recommendation statement. Rockville MD. Agency for Healthcare Research and Quality; 2008. 